\title{
Formative research to shape HPV vaccine introduction strategies in Peru
}

\author{
Rosario M Bartolini, BsocSc, ${ }^{(1)}$ Jennifer Kidwell Drake, MPH, ${ }^{(2)}$ Hilary M Creed-Kanashiro, MPhil,(1) \\ Margarita M Díaz-Otoya, BA, (1) Nelly Rocío Mosqueira-Lovón, BA, (1) Mary E Penny, MA, MBChB,, ${ }^{(1,3)}$ \\ Jennifer LWinkler, MPH, (2) D Scott LaMontagne, PhD, MPH, FRSPH, ${ }^{(2)}$ Allison Bingham, PhD. ${ }^{(2)}$
}

\author{
Bartolini RM, Drake JK, Creed-Kanashiro HM, \\ Díaz-Otoya MM, Mosqueira-Lovón NR, Penny ME, \\ Winkler JL, LaMontagne DS, Bingham A. \\ Formative research to shape HPV vaccine \\ introduction strategies in Peru. \\ Salud Publica Mex 2010;52:226-233.
}

\begin{abstract}
Objective. To understand the sociocultural environment, health systems' capacities, and policy processes related to cervical cancer and HPV vaccines in order to inform HPV vaccine introduction. Material and Methods. Mixedmethod formative research using qualitative and quantitative data collection techniques. Participants included girls, parents, community leaders, health and education officials, and policymakers. Results. Respondents, including policymakers, generally supported HPV vaccine introduction, due partly to appreciation for the benefits of vaccination and the desire to prevent cancer. Community-level concerns regarding safety and quality of services will need to be addressed. The immunization system in Peru is strong and has capacity for including the HPV vaccine. Conclusion. Formative research provides key insights to help shape an effective program for HPV vaccine introduction.
\end{abstract}

Key words: cervical cancer; qualitative research; human papillomavirus (HPV) vaccine; Peru
Bartolini RM, Drake JK, Creed-Kanashiro HM, Díaz-Otoya MM, Mosqueira-Lovón NR, Penny ME, Winkler JL, LaMontagne DS, Bingham A. Investigación formativa relacionada con el diseño de estrategias para introducir la vacuna contra elVPH en Perú. Salud Publica Mex 2010;52:226-233.

\section{Resumen}

Objetivo. Comprender el contexto sociocultural, las capacidades del sistema de salud y las condiciones políticas vinculadas al cáncer cervical y a la vacuna contra elVPH para diseñar una estrategia apropiada de introducción de la vacuna contra elVPH. Material y métodos. Investigación formativa usando técnicas cualitativas y cuantitativas. Los participantes incluyeron niños, padres, líderes, funcionarios del sector salud y educación, y diseñadores de políticas. Resultados. Generalmente se apoya la introducción de la vacuna contra elVPH, dado que se aprecian los beneficios de la vacunación y se desea prevenir el cáncer. En la comunidad se encontraron preocupaciones sobre seguridad, confianza y calidad de atención. El sistema de inmunizaciones en el Perú es eficiente y tiene la capacidad para incluir la vacuna contra elVPH. Conclusiones. La investigación formativa permite comprender elementos clave que ayudan a diseñar un programa efectivo para la introducción de la vacuna contra elVPH.

Palabras clave: cáncer de cuello uterino; investigación cualitativa, vacunas contra el virus del papiloma humano; Perú

(I) Instituto de Investigación Nutricional. Lima, Perú.

(2) PATH. Seattle, WA, USA.

(3) Harvard Medical School. Boston MA, USA. 
Pa ru has some of the highest cervical cancer incidence and mortality rates of the Latin American and Caribbean region, where at least 33000 women die annually. ${ }^{1}$ Efficacious vaccines for human papillomavirus (HPV) subtypes 16 and 18, which cause nearly $70 \%$ of all cervical cancers, ${ }^{2-6}$ present new opportunities for primary prevention.

Health systems readiness and recognition of a disease as a public health priority are key to successful vaccine introduction. ${ }^{7-9}$ Early formative research examines these factors and provides a solid evidence base for implementation. Formative studies gather information on a target audience's beliefs, values, attitudes, knowledge, and practices related to a health problem of interest, as well as the context that influences and is influenced by these individual-level factors (e.g., health systems and health policy climate). ${ }^{10}$

This paper presents results from formative research in Peru conducted as part of PATH's four-country "HPV Vaccines: Evidence for Impact" project, which aims to generate data for government decision-making and operational planning related to HPV vaccine introduction. ${ }^{11}$ Formative studies in each country consisted of sociocultural, health systems, and policy research, in order to shape a vaccine delivery strategy, a communications strategy, and an advocacy strategy. These three strategies are being implemented and evaluated in a demonstration or pilot project in each country (results published separately).

\section{Material and Methods}

The methodology in all four project countries was qualitative and guided by an ecological framework that recognizes the importance of key actors at five levels for successful vaccine introduction: individual, interpersonal, community, institutional, and policy.12,13 The research sought to obtain a wide range of experiences and informational richness in order to capture the greatest variability, since a classic representative sample was deemed neither appropriate nor feasible with this type of study design. In Peru, data were collected through a health systems assessment to map the national immunization strategy and other relevant policies, direct observation of the school-based component of a national measles and rubella vaccination campaign, and qualitative sociocultural research using focus group discussions (FGDs) and in-depth interviews (IDIs) with actors at the five levels. Data collection approaches and themes addressed in each component are listed in Table I. The formative research in Peru was conducted by the Instituto de Investigación Nutricional (IIN) between late 2006 and early 2007, with technical and financial support from PATH.

The study followed a criterion-based sampling strategy (Table II), ${ }^{14}$ and was conducted in four diverse regions, selected in consultation with Peru's Ministry of Health (MINSA): Piura (coast), Ayacucho (Andean highlands), Ucayali (Amazon rain forest) and Lima (metropolitan urban center). For the sociocultural research, health facilities and schools were selected in each of the four regions based on input from regional vaccination authorities and attainment of urban/rural diversity. ${ }^{15}$ Guides for IDIs, FGDs, and participatory techniques (Table III) were developed and modified during training of data collectors and after initial piloting in each region. Focus groups and interviews were tape-recorded, and field notes taken. Expanded field notes were created

Table I

Data collection approaches and themes for each study component. Peru, 2006-2007

Health systems assessment

Data collection approaches

Review of MINSA documents Interviews with national and regional policymakers

National vaccination strat

Vaccination schemes

Coverage

Financial resources

Storage capacity

Supply and distribution of vaccines

Safety monitoring
Structured vaccination observation

Vaccinator-child interactions

Information and materials given to parents

Teacher participation

Logistics issues

Distribution of vaccine

Reporting of statistics and measurement of coverage

Reporting of adverse events at local level
Qualitative sociocultural research

Focus group discussions (FGD)

Semi-structured in-depth interviews (IDI)

Participatory games and exercises with children and parents

\section{Cancer}

Vaccines

Health communication and information

Health and health care for 9- to I4-year-old children Reactions and attitudes toward HPV vaccines

MINSA: Ministry of Health 
Table II

Formative research sampling design by leVel of actor. Peru, 2006-2007

\begin{tabular}{|c|c|c|c|c|c|}
\hline & Individual & Interpersonal & $\begin{array}{l}\text { Communityl } \\
\text { civil society }\end{array}$ & Institutional & Policy \\
\hline Study population* & $\begin{array}{l}\text { School girls \& boys } \\
9-12 \text { years old } \\
\text { Adolescents } 13-16 \\
\text { years old }\end{array}$ & $\begin{array}{l}\text { Parents of children } \\
9-12 \text { years old }\end{array}$ & $\begin{array}{l}\text { NGOs }{ }^{\ddagger} \\
\text { Churches } \\
\text { Media }\end{array}$ & $\begin{array}{l}\text { Health managers \& } \\
\text { administrators } \\
\text { Health workers } \\
\text { Teachers } \\
\text { Immunization experts }\end{array}$ & $\begin{array}{l}\text { Local, regional, \& na- } \\
\text { tional government } \\
\text { representatives }\end{array}$ \\
\hline Data collection & $\begin{array}{l}\text { FGD } \\
\text { IDI }^{\#} \text { with graphic } \\
\text { projection methods } \\
\text { included }\end{array}$ & $\begin{array}{l}\text { FGD } \\
\text { IDI }\end{array}$ & IDI & $\begin{array}{l}\text { FGD for teachers } \\
\text { IDI for health authori- } \\
\text { ties, health workers, \& } \\
\text { teachers }\end{array}$ & IDI \\
\hline Sampling & $\begin{array}{l}\text { Criteria-based to } \\
\text { reach those who } \\
\text { would be targeted in } \\
\text { an HPV vaccination } \\
\text { program }\end{array}$ & $\begin{array}{l}\text { Criteria-based to } \\
\text { reach parents of target } \\
\text { group for vaccination }\end{array}$ & Criteria-based & Criteria-based & Criteria-based \\
\hline \multicolumn{6}{|c|}{$\begin{array}{l}\text { Criterion-based sampling, a type of purposive sampling based on predefined criteria, ensures better quality assurance. The criteria which guided sampling } \\
\text { were developed to engage the stakeholders required to assess country readiness for HPV vaccine introduction according to the project's overall concep- } \\
\text { tual framework. } \\
\text { NGO: Nongovernmental organization } \\
\text { FGD: Focus group discussion } \\
\text { IDI: In-depth interview }\end{array}$} \\
\hline
\end{tabular}

Table III

Participatory Qualitative Research techNiQUes Used With PARENTS AND CHILDRen during sociocultural research. Peru, 2006-2007

Name

Description

Free listing of health problems in their communities

Pile sorting-classification and grouping of illnesses using cards

\begin{tabular}{l} 
Analysis of analogous scenarios \\
\hline Projective photos \\
\hline Body mapping of vulnerability to cancer \\
$\begin{array}{l}\text { Development of communication "slogans" and } \\
\text { phrases }\end{array}$
\end{tabular}

Children were asked to list -individually and in groups- the health problems they perceive both now and in the future, and to "rank" them according to their perceived severity.

Children were individually given cards with the names of illnesses (e.g., influenza, tuberculosis, anemia, cancer, headache) and asked to group them according to their severity or perceived relevance. They were then asked their reasons for grouping the cards. The children could also add any other illness, including those named during the free listing exercise.

Children and parents were shown photos of middle-aged women who looked ill and were asked to describe what their problem might be and what they would do to prevent or cure their illness.

The children were presented with photos of a girl being vaccinated and were asked about the positive and negative aspects of this action.

Children were asked to draw a body and indicate where cancer could appear, both for men and women. They were asked to illustrate the location of cervical cancer.

Toward the end of the interviews and focus groups, children and parents were asked to suggest motivating phrases that could be included in a future communication campaign. for each data collection event and manually entered into textual matrixes (Table IV for a sample matrix), a recognized technique for systematically presenting, ordering, and analyzing data. ${ }^{16}$ Matrixes were organized by region, study group, and theme/ subtheme. Using a descriptive and interpretive approach outlined in detail elsewhere, ${ }^{12}$ similarities and differences in views and experiences by level of actor were compared for each theme. The aim of this analytic approach is to capture the range and variation of responses, including regional 
Table IV

Excerpt from text MatriX ${ }^{16}$ used for data analysis.* Peru, 2006-2007

Themes

\begin{tabular}{|c|c|}
\hline $\begin{array}{l}\text { Notions and } \\
\text { representa- } \\
\text { tions of } \\
\text { vaccines. }\end{array}$ & $\begin{array}{l}\text { Experiences with vaccines in } \\
\text { general. } \\
\text { Expectations about ideal vaccine }\end{array}$ \\
\hline $\begin{array}{l}\text { Experiences } \\
\text { with vaccina- } \\
\text { tion. }\end{array}$ & $\begin{array}{l}\text { Explanation of mechanism of ac- } \\
\text { tion of the vaccine/metaphor for } \\
\text { how it works in the body. }\end{array}$ \\
\hline
\end{tabular}

tion.
Subthemes how it works in the body.
Vaccines:

Vaccines are important to avoid any illness and disease, not just cancer. (AYMIIN04)

Maintains you should not believe the negative comments you hear about vaccines, because if the government approves their distribution, there is probably no ill intent associated. There is credibility of institutions and authorities. (AYMIIN04)

Vaccines as cure:

"Vaccinate when one is sick." (AYMIINOI)

The vaccine has the function of reducing symptoms in the human body. (AYMIIN06)

Vaccines as prevention:

"A girl who is up-to-date in her vaccinations almost never gets sick." (AYMIINOI,AYMIINO2)

Vaccines should be applied when one is healthy, since they are not much use when you are sick: "When an apple is already rotten, could you make it healthy? Never." (AYMIIN04)

Do not serve their purpose if applied in people who are already ill. (AYMIIN05)

"When it goes inside it protects so you can't easily get sick with any disease." (AYM3INOI)
Comments/interpretation

Predominant view:

Vaccines are good and serve to avoid getting sick, to help people to be healthy, to protect.

There is confusion about what vaccines are for. Although the majority of respondents associate them with prevention, we also encountered some confusion about their utility for curing.

\section{Minority view:}

One person associated the merits of the vaccines with the confidence they have in government agencies.

\footnotetext{
* Region:Ayacucho, Peru; Study Population: Parents of 9- to 12 -year-old children
}

$\ddagger$ Respondent identifier

variations; predominant views were also highlighted. Validation and deeper understanding were reached through continuous triangulation during regular team meetings. Triangulation involves the use of multiple theoretical perspectives, as well as data sources and methods, to enhance validity. ${ }^{17}$ Health systems data collected at each facility were collated using a spreadsheet and the results tabulated.

After preliminary analysis, participatory workshops helped to further validate the findings, as well as explore key issues in greater depth using ludic methodology. ${ }^{18}$

The formative study was approved by IIN's Ethical Committee and by PATH's Human Subjects Research Committee as a non-research activity. Written consent for children's participation in the study was provided by parents or guardians, and adults and children formally assented to be interviewed or participate in focus groups, and for interviews and focus groups to be taperecorded.

\section{Results}

As part of the health systems assessment, 24 policymaker interviews were conducted at national and regional levels. Observation of the measles and rubella campaign took place in 20 health facilities in all study regions except Lima, and included interviews with 41 health personnel and 136 adolescents. For the sociocultural research, 266 interviews and 50 focus groups were conducted in the four regions (Table V).

\section{Sociocultural}

Cervical cancer was recognized by many participants, including education, health, and civil society represen- 
Table V

Number OF FocUS GROUP AND INTERVIEW WITH EACH level of actor, by region. Peru 2006-2007

\begin{tabular}{lrrrrr}
\multicolumn{1}{c}{ Level of actor } & Piura & Ayacucho & Ucayali & Lima & Total \\
Individual & 17 & 25 & 21 & 25 & 88 \\
\hline Interpersonal & 15 & 14 & 17 & 12 & 58 \\
\hline Community/civil society & 7 & 9 & 11 & 9 & 36 \\
\hline Institutional & 31 & 30 & 33 & 23 & 117 \\
\hline Policy & 5 & 4 & 5 & 3 & 17 \\
\hline Total & 75 & 82 & 87 & 72 & 316
\end{tabular}

tatives, as a serious disease. Some parents and children referred to it more generally as a type of cancer that impacts female "intimate parts" (partes intimas).

Very few people, aside from health workers and occasional parents and teachers, knew of HPV or that it causes cervical cancer. Respondents in all groups instead cited perceived "disorders" of sexual and reproductive life as causes (e.g., infidelity, promiscuous sex). Several children, parents, and teachers attributed cervical cancer to wounds in the "intimate parts" caused by blows or strikes (golpes).

Vaccines appear well-accepted by the population (see Table IV for additional data on this topic). Children reported that vaccination enables them to avoid getting an illness and to be healthy:

She is a healthy girl, happy; she's thinking she isn't going to have illnesses now... (Child, Lima, in response to a photo of a girl being vaccinated)

Parents, members of civil society, and teachers were also largely positive about immunization.

The vaccine is a form of prevention; it's like an antidote that prevents certain viruses or germs from invading us. (Parent, Lima)

Despite general support for vaccination, fears and doubts emerged. Most children were primarily concerned about pain, and some also expressed distrust regarding the use of expired vaccines or reused or rusty needles, being forced by health workers to receive vaccines, lack of hygiene during vaccination, and viruses in the vaccine making them sick. Some girls interviewed said they would prefer gentler and more respectful treatment by, along with more information from, vaccination nurses in future campaigns. Some parents expressed concern about secondary effects of vaccination, including possible impacts on a girl's fertility:

Suspicious parents think that they're giving their daughters a vaccine to stop them having children, to ruin their uterus. (Parent, Ucayali)

Most participants responded that they would support a vaccine to prevent cervical cancer, provided that it was not experimental, side effects were fully explained in advance, and it was promoted through the existing health system. One teacher in Ucayali even suggested that "nobody in their right mind" would oppose or refuse the HPV vaccine, and one mother in the same region asked rhetorically "Who wouldn't want to be vaccinated?"

Parents and others expressed concern that the vaccine might be in a trial stage. Worries that HPV vaccination would encourage early sexual activity were only mentioned by a few parents. Others worried that the vaccine would accelerate girls' development because it is administered before sexual maturity or activity.

\section{Health systems}

The health systems assessment confirmed a strong infrastructure for immunization in Peru, including a cold chain management and delivery system. Vaccine coverage is generally high in Peru, at least 93\% (depending on the vaccine) in children less than one year old as of December 2006. The health systems review did confirm that cold chain capacity would need to increase in Ayacucho (by $91-103 \%$ ), Piura (by 57-117\%), and Ucayali (by 19-167\%) in order to accommodate the single-dose-vial packaging of the HPV vaccine. Health authorities also reported that health workers need additional training to prevent incorrect vaccination practice, including recapping needles after administration.

Although post-licensing surveillance of vaccines is relatively new, Peru has a comprehensive system for monitoring, investigating, and reporting adverse events attributed to vaccination, as well as a daily register system of vaccinations administered at each site. However, it is difficult to track whether individuals have received all doses of multiple-dose vaccines like HPV.

MINSA and other key stakeholders strongly recommended school-based delivery of the HPV vaccine. School-based immunizations, including the recent measles and rubella and yellow fever campaigns, achieved high coverage. Most individuals interviewed were supportive of a school-based vaccination strategy. Parents, for example, expressed a preference for schools because of difficulty getting their children to health centers. 
Participants also expressed some concerns regarding school-based vaccination. Some teachers and children were concerned about how adverse effects would be managed. Health workers reported that some parents mistakenly believe that those who administer vaccines in schools are actually personnel in training (practicantes) and not experienced vaccinators.

\section{Policy}

Most policymakers reported that cancer is a life-threatening disease that should be addressed by the health system, and that this perception is shared by the public:

People are very impressed by the subject of cancer, particularly if it affects the uterus, because it's an organ that means a lot to women. (Policymaker, Piura)

By contrast, other policymakers expressed concern that cervical cancer does not figure very prominently when considered in terms of other health priorities:

It's the transmissible diseases that generally predominate: respiratory, diarrheic, dermatological, and sexually transmitted ones, with cervical cancer right at the end. (Policymaker)

Other policymakers highlighted that a key challenge for prioritizing cervical cancer is a lack of accurate data on disease prevalence.

According to the policy review, resources for immunization have grown substantially in the past decade. The National Immunization Strategy's (Estrategia Sanitaria Nacional de Immunización, or ESNI) vision statement designates immunizations as the "leading activity in the public health field." Policymakers interviewed considered vaccines an important preventive health intervention.

Policymakers expressed general support for HPV vaccine introduction, and many were interested in gathering more information about the vaccine, benefits, possible side effects, cost, and the etiology of cervical cancer. Many also expressed concern about introducing a vaccine for young adolescent girls, and emphasized repeatedly that the public will need significant information and outreach on the vaccine in advance:

You'd have to disseminate the results [of previous research], what reactions it produces... it only takes one girl with a reaction... it's like a powder keg. (Regional policymaker)

\section{Discussion}

Implications of the formative research for HPV vaccine introduction strategies are discussed in the context of knowledge from developing countries, the region, and Peru.

\section{Vaccine delivery}

The formative research found that Peru's immunization system includes key vaccine delivery elements recommended by WHO. ${ }^{19,}{ }^{20}$ Peru demonstrated the highest level of childhood immunization coverage of all four project countries, which is consistent with high childhood vaccination coverage in Latin America generally. ${ }^{21,22}$ Our research also identified a need to increase storage capacity to support a single-dose presentation of HPV vaccines, to adapt the vaccine monitoring system to track this multi-dose vaccine, and to improve some health workers' vaccination practice.

Feasibility of vaccine delivery is a key contributor to achieving high coverage and vaccine acceptance. ${ }^{23}$ WHO has suggested that reaching young adolescents with the HPV vaccine in developing countries could be challenging because they are not usually included in immunization programs. ${ }^{24}$ However, recent initiatives to eliminate measles and rubella among adolescents in Latin America including school-based components have been markedly successful. Reported rubella cases in the region have dropped $98 \%$ since implementation of these programs. ${ }^{22}$ Health planners are therefore optimistic regarding feasibility of HPV vaccine introduction in Latin American countries. ${ }^{22}$

Peru recently completed a widespread measles and rubella campaign which achieved fairly high acceptance and over $97 \%$ coverage. Concerns regarding low- or non-school attendance are less relevant in Peru than elsewhere; school attendance rates in $5^{\text {th }}$ grade are estimated to be above $95 \%$, although this falls off markedly in $6^{\text {th }}$ grade and higher. ${ }^{25} \mathrm{~A}$ small group of research participants did express concerns, or alternative preferences for vaccine delivery locations, that helped pinpoint challenges to address through a comprehensive introduction strategy.

\section{Communications}

Health communication messages which address local knowledge and attitudes will likely be most effective. ${ }^{26,27}$ 
Our research found relatively low levels of knowledge of cervical cancer, especially the cause of cervical cancer, in Peru, which is consistent with other studies in the region. ${ }^{28,} 29$ The research also found widespread understanding of cancer as a deadly issue, including cancer of women's "intimate parts," also consistent with previous studies in Peru. ${ }^{30,}{ }^{31}$ Locally appropriate messages can build on existing knowledge, terminology, and attitudes to fill information gaps.

Experience with vaccine introduction efforts has also shown that anticipating and addressing community questions and concerns early is paramount for vaccine acceptance; ${ }^{23}$ this includes concerns of adolescents themselves. A 2005 guidebook from the Pan American Health Organization (PAHO) for adolescent health promotion proposes shaping health programs that respond to their often overlooked needs and concerns. ${ }^{32}$ Girls in our research expressed a desire for respectful treatment by and better information from health workers, as well as concerns regarding hygiene and safe vaccination practice. Addressing these concerns when training health workers can help meet the expressed needs of this population.

Recognition of the value of vaccination by a vaccine recipient's caretaker is also crucial to acceptance. ${ }^{27}$ To respond to concerns which were identified in our research, communications campaigns might make it clear that the vaccines are not experimental, have been widely used in developed countries with limited side effects, and are endorsed by MINSA and other local authorities. In contrast to the findings of adolescent sexual health researchers in other settings, such as North America and Europe, ${ }^{33-35}$ few respondents worried about the vaccines promoting early sexual activity among their daughters.

\section{Advocacy}

Our data were ambiguous regarding whether policymakers consider cervical cancer a public health priority, which can help facilitate vaccine introduction ${ }^{7}$; political will is key., 23 Results from Peru imply that a successful advocacy strategy might build on Peru's strong commitment to vaccination and the perception that cancer is a high-prevalence and high-fatality disease. On the other hand, our formative research findings reinforced those from other Latin American settings -that awareness of the cervical cancer burden is fairly low and that more data, information, and advocacy are needed. ${ }^{*}, 1,36$

\footnotetext{
* PATH. Developing-world policymakers' attitudes toward HPV vaccination [unpublished data]. Located at: Seattle (WA): PATH, 2005.
}

National governments in the region, including Peru, have an opportunity to capitalize on recent momentum to address cervical cancer in Latin America. In 2008, the Latin American Cancer Prevention Initiative (LACPI) was launched. ${ }^{9}$ The same year, PAHO introduced a regional strategy for cervical cancer prevention and control to its Directing Council, and a resolution was endorsed in response, committing countries to scaling up comprehensive cervical cancer programs. ${ }^{8,37}$ In addition, PAHO's ProVac Initiative provides a framework for governments in the region to tackle decision-making regarding HPV vaccine introduction in an accelerated fashion, and the PAHO Revolving Fund can enable countries to purchase vaccines at more affordable prices. ${ }^{22}$

\section{Conclusion}

The formative research in Peru found that individuals at five levels of influence are supportive of HPV vaccine introduction in their communities. Respondents shared concerns about safety and quality of care. There was a strong preference for school-based vaccine delivery, and the research confirmed that Peru has a robust vaccine delivery system in place. These findings were applied to help shape three strategies-vaccine delivery, communications, and advocacy- that were tested in a demonstration project in May 2008 in partnership with MINSA. Data from that work are undergoing analysis at the time of this writing, but early indications are that coverage and acceptance of the vaccine were reasonably high. The results of this formative research and the demonstration project, together with those of the other three countries, will supplement a small but growing evidence base for HPV vaccine introduction throughout the developing world.

\section{References}

I. Parkin DM,Almonte M, Bruni L, Clifford C, Curado M, Pineros M. Burden and trends of type-specific human papillomavirus infections and related diseases in the Latin America and Caribbean region.Vaccine 2008;26(Suppl II):LI-LI5.

2. Koutsky LA,Ault KA, Wheeler CM, Brown DR, Barr E,Alvarez FB. A controlled trial of a human papillomavirus type 16 vaccine. $N$ Engl J Med 2002;347(2I):1645-165I.

3. Ling M, Kanayama M, Roden R, Wu TC. Preventive and therapeutic vaccines for human papillomavirus-associated cervical cancers.J Biomed Sci 2000;7(5):34I-356.

4. Hildesheim A, Markowitz L,Avila MH, Franceschi S. Research needs following initial licensure of virus-like particle HPV vaccines. Vaccine 2006;24(Suppl 3):227-232.

5. Burchell AN, Winer RL, de Sanjose S, Franco EL. Epidemiology and transmission dynamics of genital HPV infection.Vaccine 2006;24(Suppl 3):52-61. 
6. Clifford G, Franceschi S, Diaz M, Munoz N,Villa LL. HPV typedistribution in women with and without cervical neoplastic diseases. Vaccine 2006;24(Suppl 3):26-34.

7.World Health Organization (WHO), Department of Immunization, Vaccines and Biologicals. Vaccine Introduction Guidelines:Adding a Vaccine to a National Immunization Programme: Decision and Implementation. Geneva (Switzerland):WHO, 2005.

8. Pan American Health Organization (PAHO). Regional Strategy and Plan of Action for Cervical Cancer Prevention and Control. Washington (DC): PAHO, 2008.

9. Correa P.The war against cervical cancer in Latin America and the Caribbean. Triumph of the scientists. Challenge for the community.Vaccine 2008;26(Suppl II):iii-iv.

10. Newes G, Helitzer DL, Caulfield LE, Borwn KH. Theory and practice: applying the ecological model to formative research for a WIC training program in New York State. Health Educ Res 2000; 15(3):283-29I. II.Wittet S. Cervical cancer vaccine project [fact sheet]. Seattle (WA): PATH, 2006.

12. Bingham A, Janmohamed A, Bartolini R, Creed-Kanashiro H, Katahoire $A$, Khan I, et al.An approach to formative research in HPV vaccine introduction planning in low-resource settings. The Open Vaccine Journal 2009;2:I-16.

13. Green LM, Kreuter MW. Health Promotion Planning:An Educational and Ecological Approach. 3rd ed. Mountain View (CA): Mayfield, 1999.

14. Kuzel AJ. Sampling in qualitative inquiry. In Crabtree BF, Miller WL, eds. Doing Qualitative Research. Newbury Park, CA: Sage Publications, 1992 33-46.

15. PATH, Instituto de Investigación Nutricional (IIN). Shaping a Strategy to Introduce HPVVaccines in Peru: Formative Research Results from the HPV Vaccines: Evidence For Impact Project. Seattle (WA): PATH, 2009. 16. Miles MB, Huberman AM. Qualitative Data Analysis: An Expanded Sourcebook. Thousand Oaks (CA): Sage Publications, 1994.

17. Gilchrist VJ. Key informant interviews. In Crabtree BF, Miller WL, eds. Doing Qualitative Research. Newbury Park, CA: Sage Publications, 1992: 70-89.

18. Creed-Kanashiro HM, Bartolini RM, Fukumoto MN, Uribe TG, Robert RC, Bentley ME. Formative research to develop a nutrition education intervention to improve dietary iron intake among women and adolescent girls through community kitchens in Lima, Peru. J Nutr 2003; I33(I I Suppl 2):3987S-399/S.

19. World Health Organization (WHO). Training for Mid-Level Managers: Cold Chain,Vaccines and Safe-Injection Equipment Management. Geneva (Switzerland):WHO, 2008.

20. United States Agency for International Development (USAID). Immunization Essentials:A Practical Field Guide.Washington (DC): USAID, 2003.

21. Biellik R, Levin C, Mugisha E, LaMontagne DS, Bingham A, Kaipilyawar S, et al. Health systems and immunization financing for human papillomavirus vaccine introduction in low-resource settings. Vaccine 2009;27(44):62036209.
22.Andrus JK, Lewis MJ, Goldie SJ, García PJ,Winkler JL, Ruiz-Matus C, et al. Human papillomavirus vaccine policy and delivery in Latin America and the Caribbean.Vaccine 2008;26(Suppl II):L80-L87.

23. Winkler JL,Wittet S, Bartolini RM, Creed-Kanashiro HM, LazcanoPonce E, Lewis-Bell K, et al. Determinants of human papillomavirus vaccine acceptability in Latin America and the Caribbean. Vaccine 2008;26(Suppl II):L73-L79.

24. World Health Organization (WHO), United Nations Population Fund. Preparing for the Introduction of HPV Vaccines: Policy and Programme Guidance for Countries. Geneva (Switzerland):WHO, 2006.

25. Instituto Nacional de Estadística e Informática (INEI). Compendio Estadístico 2006. Lima (Peru): INEI, 2006.

26. Kaljee LM, Pack R, Pach A, Nyamete A, Stanton BF. Sociobehavioural research methods for the introduction of vaccines in the Diseases of the Most Impoverished Programme.J Health Popul Nutr 2004;22(3):293-303. 27. Jheeta M, Jewell J. Childhood vaccination in Africa and Asia: the effects of parents' knowledge and attitudes. Bull World Health Organ 2008;86(6):419.

28. Garcia SG, Becker D, Tatum C,Aldrich T, Fernandez CA. Linking cervical cancer to the human papillomavairus: findings from a qualitative study with Mexican women. Health Care Women Int 2007;28(2): 192-205. 29. Moreira Jr. ED, Oliveira BG, Ferraz FM, Costa S, Costa Filho JO, Karic G. Knowledge and attitudes about human papillomavirus, Pap smears, and cervical cancer among young women in Brazil; implications for health education and prevention. Int J Gynecol Cancer 2006; 16(2):599-603. 30.Agurto I, Bishop A, Sánchez G, Betancourt Z, Robles S. Perceived barriers and benefits to cervical cancer screening in Latin America. Prev Med 2004;39(I):91-98.

3I. Bingham A, Bishop A, Coffey P,Winkler J, Bradley J, Dzuba I, et al. Factors affecting utilization of cervical cancer prevention services in lowresource settings. Salud Publica Mex 2003;45(Suppl 3):S408-S4I6. 32. Pan American Health Organization (PAHO). Youth: Choices and Change; Promoting Health Behaviors in Adolescents. Washington (DC): PAHO, 2005.

33. Zimet GD, Liddon N, Rosenthal SL, Lazcano-Ponce E,Allen B. Chapter 24: Psychosocial aspects of vaccine acceptability.Vaccine 2006;24(Suppl 3):20I-209.

34. Kahn JA, Burk RD. Papillomavirus vaccines in perspective. The Lancet 2007;369(9580):2।35-2। 37.

35. Mays RM, Sturm LM, Zimet GD. Parental perspectives on vaccinating children against sexually transmitted infections. Soc Sci Med 2004:58(7):1405-14|3.

36. Almonte M,Albero G, Molano M, Carcamo C, Garcia PJ, Perez GI. Risk factors for human papillomavirus exposure and co-factors for cervical cancer in Latin America and the Caribbean.Vaccine 2008;26(Suppl II):LI6-L36.

37. Luciani S,Andrus JK.A Pan American Health Organization strategy for cervical cancer prevention and control in Latin America and the Caribbean. Reprod Health Matters 2008;16(32):59-66. 